\title{
Signature concepts of key researchers in North American higher education teaching and learning
}

\section{Peter Kandlbinder}

Higher Education

The International Journal of Higher Education Research

ISSN 0018-1560

Volume 69

Number 2

High Educ (2015) 69:243-255

DOI 10.1007/s10734-014-9772-7

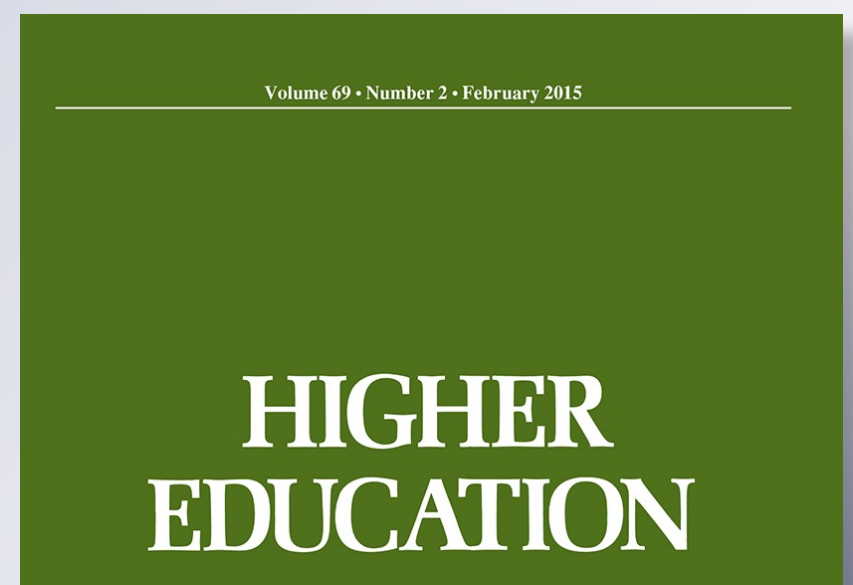

the international journal of higher education research

Springer 
Your article is protected by copyright and all rights are held exclusively by Springer Science +Business Media Dordrecht. This e-offprint is for personal use only and shall not be selfarchived in electronic repositories. If you wish to self-archive your article, please use the accepted manuscript version for posting on your own website. You may further deposit the accepted manuscript version in any repository, provided it is only made publicly available 12 months after official publication or later and provided acknowledgement is given to the original source of publication and a link is inserted to the published article on Springer's website. The link must be accompanied by the following text: "The final publication is available at link.springer.com". 


\title{
Signature concepts of key researchers in North American higher education teaching and learning
}

\author{
Peter Kandlbinder
}

Published online: 6 June 2014

(C) Springer Science+Business Media Dordrecht 2014

\begin{abstract}
Universities in the English-speaking world share a common ancestry that extends back to medieval times. From these beginnings universities quickly developed distinctive qualities as they became integrated within different social and cultural systems of their home societies. A number of comparisons of higher education research have shown major differences developed between North American and non-North American higher education literature inviting conclusions that higher education research communities are largely separate. Drawing on Bourdieu's concept of empirical field research this paper reviews the research literature in three North American journals focused on higher education teaching and learning to identify six researchers who the journals' authors consider central to the field. A second level analysis of the citations within this literature revealed that these researchers were associated with developing five distinctive signature concepts used by authors to support their arguments about higher education teaching and learning. By comparing the five signature concepts of the North American field of higher education teaching and learning with the five signature concepts of the non-North American literature this study concludes that there is some, albeit small, conceptual common ground on which to build collaboration between the two distinctive research fields.
\end{abstract}

Keywords Signature concepts $\cdot$ Scholarly publishing $\cdot$ Higher education teaching and learning

\section{Introduction}

A signature concept is a powerful idea for looking at differences in higher education research. Signature concepts as those ideas that have become so well recognised as belonging to a researcher or research tradition that authors in higher education are more

P. Kandlbinder $(\bowtie)$

Institute for Interactive Media and Learning, University of Technology, Sydney, Sydney, Australia e-mail: Peter.Kandlbinder@uts.edu.au 
likely to use that version of the concept over any other version in the field. Signature concepts discussed in this article developed as a result of the struggle for recognition and status that serves the scholarly publishing practices of the higher education teaching and learning field. This is the result of the sum total of decisions made by academic authors, reviewers and editors who choose specific researchers to cite to support the legitimacy of their arguments. After many thousands of contributions to the higher education literature rules have arisen which endow the work of selected researchers with positive or negative properties and position them in the scholarly publishing field accordingly. The result of this competition for recognition among academic authors is an academic literary field that has a differentiated, hierarchical structure of researchers positioned in relation to other researchers in the field (see Bourdieu 1983, 1985).

In this study I take up Bourdieu's argument that the literary field is a social space that can best be understood by describing the underlying logic that positions different actors in relation to each other. To ascertain which concepts are central to the North American field of higher education I have undertaken a study of the signature concepts cited in the three most prestigious journals on higher education teaching and learning in the North American field (as recognized by Tight 2007). Through a process of intertextual analysis I identified five signature concepts of the North American field of higher education teaching and learning which I compared to the five signature concepts previously identified in the nonNorth American literature (see Kandlbinder 2013). As a result of this comparison I conclude that it is only by understanding the concepts of a field are we able to collaborate in ways that will bring the different interpretations of teaching and learning closer together.

\section{Steps towards identifying the logic of the North American field of higher education teaching and learning}

To determine the rules in play for the North American higher education field I undertook a citation analysis of the articles of the three North American-based journals identified by Tight (2007) in four stages. Tight nominated the three leading North American academic journals for higher education teaching and learning research as the Journal of Higher Education, Research in Higher Education and Review of Higher Education. I began this analysis of signature concepts by identifying the researchers who are most referenced in each of these three journals. I then sorted the reference lists of these researchers to find their main publication cited by the journal's authors. Next, the citations for this publication were reviewed in each article to see what assertions were being supported by the literature.

For continuity purposes the analysis of the three journals begins in the same year analysed by Tight (2007) and extended over 30 issues of each journal. Thirty issues was selected in my initial study to span a minimum 5 year period preferred by authors when citing the literature and still provide an approximately equal number of articles for comparison across all journals. The time period for this sample spans 2000-2005 due to the varying number of issues for each journal. This resulted in 17,466 references from 884 articles.

When the reference lists of these articles were ranked by first author, the count of the references over the 30 issues fell into three broad bands. Of the 10,092 researchers referenced in the reviewed articles only $29 \%$ were cited more than once within the collected reference lists. Of the group of researchers who were referenced multiple times there was an average of 6 researchers (ranging from 2 to 8) who stood alone in their respective journals as being referenced more than any other group of researchers, as shown in Table 1 below. 
Table 1 Top 10 referenced researchers in North American-based Higher Education Journals $(\mathrm{n}=$ total number of references)

\begin{tabular}{llll}
\hline & Journal of HE & Research in HE & Review of HE \\
\hline 1 & Pascarella, E. T. $(\mathrm{n}=89)$ & Pascarella, E. T. $(\mathrm{n}=110)$ & Astin, A.W. $(\mathrm{n}=104)$ \\
2 & Astin, A. W. $(\mathrm{n}=85)$ & Astin, A. W. $(\mathrm{n}=101)$ & Pascarella, E. T. $(\mathrm{n}=83)$ \\
3 & Tierney, W. G. $(\mathrm{n}=47)$ & St. John, E. P. $(\mathrm{n}=73)$ & Kuh, G. D. $(\mathrm{n}=54)$ \\
4 & Kuh, G. D. $(\mathrm{n}=42)$ & Tinto, V. $(\mathrm{n}=73)$ & Hurtado, S. $(\mathrm{n}=53)$ \\
5 & St. John, E. P. $(\mathrm{n}=40)$ & Smart, J. C. $(\mathrm{n}=67)$ & National Center for Educational \\
& & & Statistics $(\mathrm{n}=50)$ \\
6 & Tinto, V. $(\mathrm{n}=37)$ & Kuh, G. D. $(\mathrm{n}=62)$ & Tierney, W. G. $(\mathrm{n}=49)$ \\
7 & Clark, B. R. $(\mathrm{n}=36)$ & Marsh, H. W. $(\mathrm{n}=61)$ & Tinto, V. $(\mathrm{n}=35)$ \\
8 & Boyer, E. L. $(\mathrm{n}=30)$ & Tierney, W. G. $(\mathrm{n}=49)$ & Slaughter,.$(\mathrm{n}=31)$ \\
9 & Braxton. J. $(\mathrm{n}=29)$ & Feldman, K. A. $(\mathrm{n}=48)$ & St. John, E. $(\mathrm{n}=31)$ \\
10 & Pace. C. R. $(\mathrm{n}=29)$ & Cabrera, A. F. $(\mathrm{n}=45)$ & Clark, B. R. $(\mathrm{n}=31)$ \\
\hline
\end{tabular}

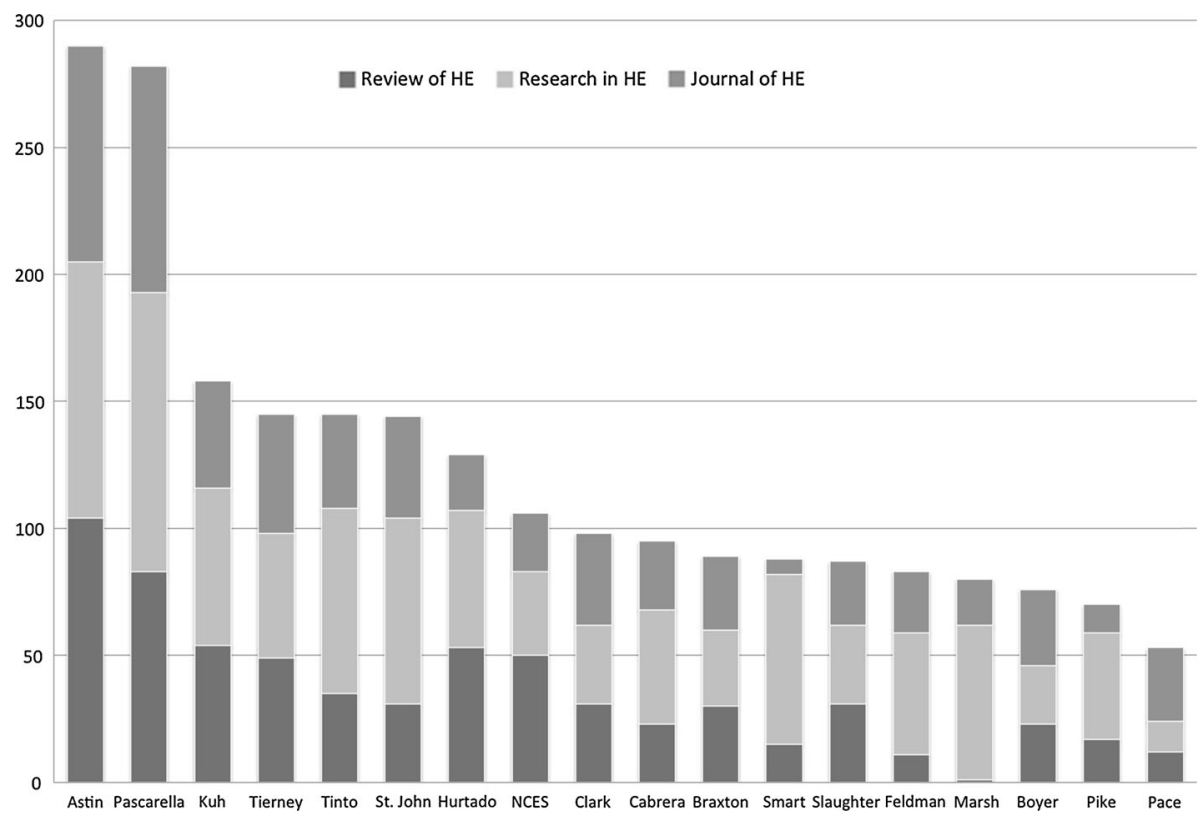

Fig. 1 No of references to researchers in three North American-based higher education journals

A count of references across all three journals showed that the six most commonly referenced researchers were Astin $(\mathrm{n}=290)$; Pascarella $(\mathrm{n}=282)$; Kuh $(\mathrm{n}=158)$; Tierney $(\mathrm{n}=145)$; Tinto $(\mathrm{n}=145)$; and St. John $(\mathrm{n}=144)$.

Before moving to the analysis of signature concepts, the question of ranking by first author and joint authorship needs to be addressed. In these three journals $71 \%$ the researchers were only referenced once throughout the 5-6 year sample period. In order to be included in the final list researchers must have been referenced as first author more than any other researcher across all three journals, as shown in Fig. 1. 
In the case of second authors of widely cited articles, like Elizabeth Whitt or Estela Bensimon, their names are well down the reference lists in regards to their other, first authored work. This does not deny the major contribution made by additional authors in highly cited publications. It does, however, highlight that the contribution to the conceptual development of a field goes beyond a single, highly cited work if it is to be recognized as a signature concept. Even in the case of Pascarella and Terenzini, $64 \%$ of Pascarella's references as first author are not written with Patrick Tezzerini. However, the extremely high citation rate for their co-authored book makes it difficult to attribute responsibility for the concept cited by the journal authors solely to Pascarella. Therefore, I have retained the convention of linking signature concepts to a body of work attributed to the first authors even for multi-authored articles except for Pascarella and Terenzini. In their case, the signature concept identified by a single co-authored book is attributed to both authors while acknowledging that Terenzini would be unlikely to be cited for a signature concept in his own right as he is well down the reference lists as a first author.

\section{Six concepts associated with the highly referenced researchers in North American higher education}

Analysing the citations in each of the six researchers' most referenced publication involved categorizing the concept in a sentence labelled with a citation by the author. The concept was identified through the reporting verb used by the author to indicate his or her actions, beliefs and thoughts, as suggested by Thompson and Ye Yiyun (2001). The concepts were classified using keywords, or where no self-identifying phrase existed, a phrase I assigned to a category. Cases of self-citation were common and were omitted from the analysis. The final set of concepts was further examined to determine the strength of the relationship between concepts and citations, with the citations ordered from the numerically strongest to the weakest associations. In each case, what is reported here is what the authors say about the cited research. I have tried to keep the categories as close to the author's own words as possible. In most cases I have adopted a single author's label to represent all the authors who discussed the same concept. Where multiple publications have been cited across the journals, I have presented them in chronological order.

\section{Alexander W. Astin: Racial diversity}

The authors in the Journal of Higher Education, Research in Higher Education \& Review of Higher education mostly cited Astin (1993) to identify factors impacting on student success in order to design their own empirical study on students' college experiences. Most authors identified a research variable relevant to their study and the majority of variables discussed were mention once or twice in the sample. Of the research variables that were mentioned more than twice, the concept recognized by most authors as associated with Astin's work was the positive impact of racial diversity in colleges. This could be through interaction by students from different racial or ethnic groups, variety in the attitudes about racial discrimination and racial understanding, or diversity-related activities like awareness programs. These interactions were claimed to improve student-learning outcomes, civic and community-service behaviours and commitment to social justice.

Many authors also discussed the influence of the student's peer group to a successful learning experience in college. These authors identified peers as the single most potent source of influence in the student experience and therefore were central to a successful 
learning experience. Peers were described as influencing various student outcomes by facilitating students' academic integration, influencing how students spend their time and the meaning they make of their college experiences, including their personal satisfaction with college.

\section{Ernest T. Pascarella \& Patrick T. Terenzini: Student-faculty interaction}

Like the citations for Astin (1993), the majority of authors across the three journals cited Pascarella and Terenzini (1991) to identify research variables in relation to traditional college student experiences in order to collect empirical data in their own studies. Similarly, most authors discussed a research variable relevant to their study and the majority of variables were cited only once or twice across the sample articles. Of the research variables cited more than twice, the most common issue discussed citing Pascarella and Terenzini (1991) was the positive influence of student-faculty interaction on student experiences of higher education. The focus was principally on lower student-faculty ratios and smallersized colleges, which were claimed to be better for student development. These authors discussed both the frequency and nature of the interaction, arguing that formal and informal contact which focuses on academic and career matters has the greatest impact on student success when compared to solely social exchanges.

Many authors also cited evidence of peer influence on learning. They argued that peers serve a vital educational function as they engage students more deeply in the college experience and thereby enhance their learning. Some authors went so far as to argue that the peer group was the dominant change agent during the college years.

Those authors who discussed the outcomes of college attendance did so primarily in terms of benefits for future earnings. They argued that college quality had a positive and statistically significant—albeit a generally small—effect on earnings that declines over time.

George D. Kuh: Institutional culture

Authors in Review of Higher Education cited Kuh and Whitt (1988) as researchers who applied cultural theory to higher education settings. These authors argued that demographic characteristics effect how faculty experience academic culture with subcultures each having different interpretations of organizational reality. They suggested that webs of significance form an "invisible tapestry" in an organization and permanent change comes from congruence between artefacts, values, and espoused values in which interviews can be used to explore motivation, meaning-making and behaviour.

Authors in Journal of Higher Education cited Kuh et al. (1991) to discuss the importance of the institutional mission as a major influence on distinctive student cultures.

Some authors in Research in Higher Education cited Kuh et al. (1997) to discuss cognitive development and the dimensions related to educational outcomes while other authors cited Kuh et al. (2001) to have a theory of student involvement and to provide empirical evidence on validity of self-reports.

William G. Tierney: Faculty socialization

Most authors in Review of Higher Education and Journal of Higher Education used Tierney and Bensimon (1996) to describe the process of socialization that takes place when 
new faculty begin their probationary membership in a department and concludes with the granting of lifetime tenure. They described socialization as a highly charged process that orients individuals to organizational beliefs and attitudes, which often represent teaching as undervalued and research as important. These authors referred to the track towards tenure as a major force for socialization. It creates a faculty experience that is stressful due to the ambiguity of tenure expectations that discriminate against minority faculty and pitches teaching against research. As a result newcomers feel isolated and perceive a lack of collegiality that challenges their expectations of faculty life.

Some authors also described the different demographic characteristics that affect the academic culture and rewards, and lead to an underrepresentation of minorities in departments, feelings of constantly working and a lack of accommodation of non-work life.

\section{Vincent Tinto: Student persistence}

Like Pascarella and Terenzini (1991), Astin (1993) the majority of authors in Journal of Higher Education, Research in Higher Education \& Review of Higher Education cited Tinto (1993) to identify research variables in relation to students experiences of college in order to collect their own empirical data. Most authors identified a variable relevant to their own study and the majority of variables were mention only once or twice in sample. Of the variables that were mentioned more than twice, the most common issue relating to Tinto's (1993) study were the factors that influence student persistence. Tinto was identified as conducting persistence, attrition, and retention studies that lead to a model of persistence. This model took into account parents' background, students' ability, as well as students' behaviours in becoming involved in campus life. Numerous individual and institutional factors were said to influence student attrition. In descending order these were belonging and "fit" with the institution, gender, student involvement in college, low socio-economic backgrounds, degree of successful integration into the academic and social structures, institutional commitment, students' academic or career plans and persistence in school.

Many authors also considered the consequences of student departure from college for various student populations. The different institutional settings and stages in time was seen as crucial in the quest to improve retention rates. It was noted that only a small percentage of institutional departures arise because of academic failure. Instead it is disengagement that takes a toll in terms of academic performance and satisfaction, and correlates with premature departure from college.

Edward P. St. John: Student financial aid

Of all the researchers in the sample, St. John was cited for the widest variety of publications. Rather than a signature concept it is perhaps more accurate to describe the influence of financial aid on enrolment as a consistent theme in his work. The references are ordered chronologically to demonstrate how the dominant theme continued over the sample period.

In Journal of Higher Education St. John was referenced for 5 publications. Authors used St. John and Noell (1989) to explain enrolment behaviour, especially among students of different racial/ethnic groups. Some authors discussed the effects of financial aid among minority groups and the effects of assessment. Authors cited St. John et al. (1991) to identify factors relating to persistence, such as student aid, parents' education or college grades. Authors cited St. John (1994) to note financial aid is comprised of pecuniary and 
non-pecuniary aspects. Authors cited St. John et al. (1994) to raise questions about the role of financial aid and how to determine whether aid is sufficient. Authors cited St. John and Starkey (1995) to note that price-response measures could change over time or vary by the students' year in college.

In Research in Higher Education authors cited St. John (1990a, b) to describe how the increase in financial aid increases enrolments, looked at financial factors and undertook earlier student college choice research.

In Review of Higher Education St. John was referenced for 3 publications each describing the effect a different component of financial aid has on enrolment. Authors used St. John $(1990 \mathrm{a}, \mathrm{b})$ to discuss tuition effects that are greater with lower income students and positive effects related to income. Authors used St. John (1999) as an example of multivariate regression that addresses omitted variable bias in the financial aid literature. Authors used St. John (2003) to discuss how enrolment decisions are influenced by the costs of attendance.

\section{The logic of the North American higher education field}

Authors in North American-based journals of higher education teaching and learning cite previous research for a variety of reasons. These decisions about what literature best supports their arguments leads to a contest among researchers that results in an objective organization of a field without any conscious intention of promoting particular researchers on the author's part. The result is that the research literature acts as a reference point for authors with both a hierarchy of concepts and a hierarchy of authors.

The pattern of citation practices reported in this article show authors in North American-based journals of higher education teaching and learning will more likely turn to six researchers when discussing student experiences of higher education. Each of these researchers has produced a significant body of work but is more likely to be cited for a "signature" concept. That is, four of the researchers were on average cited for one publication and that publication was largely used to discuss a single concept, often for little more than identifying a research variable in need of further investigation. Kuh and St John were cited for a range of publications but in each case the theme across these publications was strongly related to a single concept. As a result, all of these signature concepts were more likely to be associated with a particular researcher even in cases where a range of researchers discuss the same concept in the same field.

A further look at the concepts discussed above shows that the association between concepts and individual is not linear. Comparing the number of citations across all three journals with the different researchers attributed with developing those ideas shows that the authors in higher education teaching and learning write more about some concepts than others. In these cases they are also likely to cite more than one researcher to support their discussions.

This is illustrated in Fig. 2 where the x-axis is the number of different researchers attributed to a particular concept. The y-axis shows the total number of times a concept was cited by authors across the sample articles. The upper right quadrant in Fig. 2 demonstrates five concepts are on average cited more often than others and attributed to two or more researchers.

In summary, while it is true that when discussing the idea that student persistence, Tinto was the citation of choice for most authors, this concept was also associated with three other researchers. When discussing peer interaction authors were more likely to turn to 


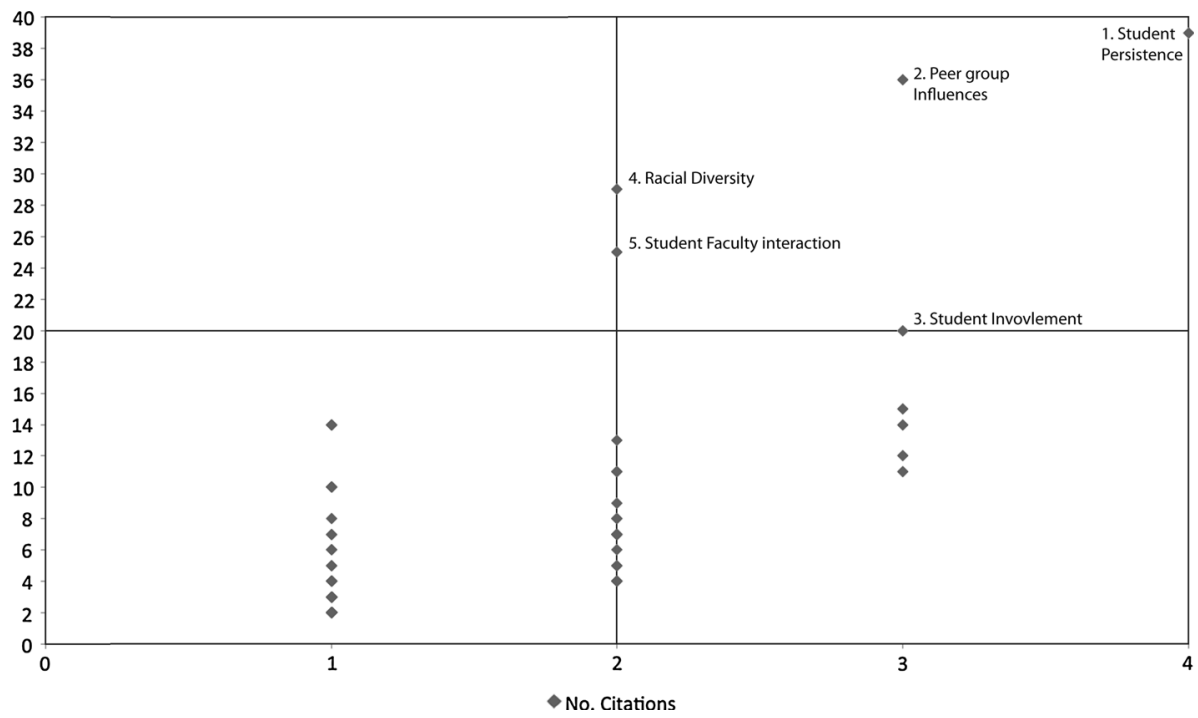

Fig. 2 Five signature concepts of the North American field of higher education teaching and learning

three researchers to support their arguments, although this was not the signature concept for any of them. This was the same for the concept of student involvement. On matters of racial diversity Austin was the researcher cited ahead of others but this concept was also associated with a second researcher, who was likewise associated with the idea of studentfaculty interaction.

In the case of institutional culture, student financial aid and faculty socialization, which these were all significant individual signature concepts for three highly cited researchers (and were at the top of lower left quadrant in Fig. 2), these concepts were not discussed on average any more than others in the literature. They therefore cannot be considered signature concepts for the field.

\section{Comparing the North American and non-North American signature concepts}

When comparing North American higher education literature to the research results reported in English speaking literature published elsewhere, Tight (2007) found that North American articles were dominated by North American-based authors who concentrated to a greater extent on the student experience of college than the topic of course design that was more common in the non-North American literature. In addition, there was a much stronger emphasis on multivariate analysis used as a research method to study these student experiences at the national level. Tight (2007) explained the differences in the North American and non-North American literature as largely due to the size and distinctiveness of the North American higher education system.

Haggis (2009) expanded on Tight's study by reviewing the titles of articles in the higher education journals nominated by Tight. She found themes addressed in article titles in North American higher education journals from 1970 to 2007 were somewhat different to those identified in non-North American contexts. The non-North American journals in the 
1970s focused on building a knowledge base about student learning that shifted to more critical perspectives in the 1980s and shifted again in the 1990s to a greater interest in classroom practice. By the 2000s, the non-North American journals were relatively consistent in the kinds of psychologically-based research they published and were becoming less interested in publishing discussions of classroom practice than social and critical perspectives. By comparison the North American journals had far fewer articles devoted to discussing curricular innovation and preferred research approaches used within cognitive psychology with a large number of titles reflecting various types of social contexts such as race, colour and disadvantage. In the North American literature titles increasingly concentrated on issues of persistence, withdrawal and retention throughout the decades, often focusing explicitly on their relationship to what were called "non-traditional" students (Haggis 2009, p. 27).

In my own study of non-North American higher education literature inspired by Tight (2003) I found that authors in the four most prestigious journals in the field discussed five signature concepts when considering higher education teaching and learning (Kandlbinder 2013). Authors in four journals of higher education recognized the big ideas of deep and surface approaches to learning, constructive alignment, a relational view to how context influences teaching and learning, and critical thinking contribute to answering five important questions to higher education teaching and learning.

Comparing the signature concepts of the two fields also supports what Tight and Haggis found regarding little overlap in North American and non-North American higher education research. Table 2 shows authors in the non-North American literature do not refer to the same signature concepts as their North American-focused counterparts. On average non-North American authors were more concerned with understanding why students behave in certain ways than testing a dependent variable like student persistence against factors leading to that variable. Instead of a few factors leading to an outcome the nonNorth American literature authors described the logic of associations between a family of concepts largely developed by asking students how they approach their learning. This research was led by researchers following phenomenographic methods, which, while not the dominant research method in higher education research, has been highly influential by demonstrating the importance of a relational view that context influences both learning and teaching. The closest analogy to a dependent variable in the non-North American field has become deep and surface approaches to learning and the most influential independent variable relating to approaches to learning has been found to be assessment.

On the few occasions when authors in the North American literature do discuss nonNorth American signature concepts they tend to use different publications to discuss the motivational constructs that predict student success. That is, they are more likely to refer to

Table 2 Signature concepts for the North American and non-North American field of higher education teaching and learning

\begin{tabular}{lll}
\hline & North American higher education & Non-North American higher education \\
\hline 1. & Student persistence & Student approaches to learning \\
2. & Peer interaction & Deep and surface approach to learning \\
3. & Student involvement & Conceptions of teaching \\
4. & Racial diversity & Context influences learning \\
5. & Student-faculty interaction & Assessment-driven learning \\
\hline
\end{tabular}


Entwistle and Tait (1995) to discuss the basis for understanding students' perceptions and interpretations of the academic requirements than Entwistle and Ramsden's (1983) findings of the environment's affect on their approaches to learning favoured in the non-North American field. Similarly, when referring to the work of Biggs (1978, 1987), North American authors discuss an approach to learning in which students have a focus on assessment instead of his signature concept of 'constructive alignment' (Biggs 1999). Moreover, when North American authors cite non-North American authors who have developed individual signature concepts, they discuss their non-signature concepts, such as the research-teaching nexus (Barnett 1992; Ramsden and Moses 1992) and the role that academics play in intellectual life of universities (Barnett 1994).

Conversely, non-North American authors are only slightly more likely to cite research from a different higher education field than their North American counterparts. Indeed, they too do not refer to the North American field's signature concepts. Like their North American-focused colleagues they refer to North American research when they want to repeat quantitative studies in different settings or confirm previous research.

A further difference in the two fields is the absence of signature concepts associated with individual researchers. In the non-North American literature the upper left quadrant in Fig. 2, which shows a single researcher being cited on average more than others in the field, there were three concepts discussed in more detail than any others. In these cases authors used the individual signature concepts from Noel Entwistle, Ference Marton and Ronald Barnett to support their arguments about the utility of the Approaches to Study Inventory, phenomenographic methods of analyzing variation and the idea of a critical being (Kandlbinder 2013).

Nevertheless, there are some areas of conceptual overlap between the two fields. Authors in all seven journals discussed conceptions of teaching, although again the different fields took slightly different approaches. The North American literature preferred to discuss the demographic characteristics of university teachers and their effect on how faculty experience academic culture (Kuh and Whitt 1988). It also described the process of socialization that orients individuals to organizational beliefs and attitudes and takes place when new faculty join a department (Tierney and Bensimon 1996). In the non-North American field, the signature concept was faculty's conceptions of teaching and their influence on teaching strategies. This could be through various links between perceptions of learning environment impacting on approaches to learning (Trigwell and Prosser 1991), the match between conceptions of teaching and the intention teachers have for their teaching (Trigwell and Prosser 1996), the link between teachers approaches to their teaching and the ways their students approach their learning (Trigwell et al. 1999), teaching approaches changes according to context (Prosser and Trigwell 1999) or the relationship between teachers' beliefs and higher quality student learning outcomes (Prosser and Trigwell 1999).

Finally, the point of convergence between the two fields comes outside of the field's signature concepts and unites on the question of universities becoming increasingly focused on economic considerations rather than by concern for enhancing teaching and learning. This is a process that Slaughter and Leslie (1997) called "academic capitalism" (p. 8). Authors in both the North American and non-North American fields cited Slaughter and Leslie (1997) to introduce the concept of academic capitalism, propose concepts within this theoretical framework or outline the hallmarks of academic capitalism. These were defined as the sorts of actions intended to attract external revenue for higher education institutions and is synonymous with the commodification of teaching and the commercialization of research. Academic capitalism was seen as a key driver in changes to 
the work that academics do, with authors discussing global economic forces that lead to the rise in market activity in higher education and resulted in educational policies that restructure higher education along entrepreneurial lines where universities embrace corporate values that focus more on the economic bottom-line.

\section{Conclusion}

The multivariate logic of North American higher education teaching and learning research is to enumerate, describe and list factors related to the outcome of students staying at college. Researchers studying the North American higher education system attempt to answer the question of what keeps students in university by classifying the factors that lead to a lack of success and undertaking statistical analysis to isolate factors that has the strongest influence on reversing that effect. The outcome of this logic is the more researchers are able to quantify the different components of higher education the better they will understand questions related to teaching and learning. In order to identify elements impacting on student persistence North American authors turn to six researchers who are central in the construction of five signature concepts for the North American higher education field. The variables discussed in the literature identify social interaction (peer-to-peer and student-faculty) and student involvement in activities in their college as critical factors to students' sense of belonging and wellbeing. It is this sense of belonging that is responsible for student persistence throughout their studies. The cultural variable most likely to impact on a sense of belonging in the North American context was racial diversity.

Tight (2007) and Haggis (2009) provided two initial studies that described the differences in North American and non-North American higher education research. Both authors speculated on ways the two fields could be brought closer together. Tight imagined that as higher education systems grow closer in size they will develop similar characteristics and provide the grounds for greater collaboration between higher education researchers. However, since that original prediction the European higher education system has grown in size comparable to the North American system and divided from the existing scholarly literature to create a third sub-field of higher education teaching and learning research (Tight 2012). Similarly, Haggis showed the different research traditions operating in the two fields and suggested that other fields like adult education or academic literacy might form the common ground that could bring the two fields closer together, although there was no evidence of that occurring in this study.

What this study does demonstrate is that there can be no movement within or across fields without understanding the underlying rules that govern the reputation and prestige of researchers in a field and suggesting alternatives fields only moves the challenge to a different location. Instead of relying on system size or other research traditions to form a bridge between two fields, this analysis of signature concepts has begun a process of identifying the conceptual similarities that currently exist between the two fields. This study has been able to show that there is enough common conceptual ground for the fields to collaborate based on signature concepts that have evolved from within their own fields. Authors in the North American and non-North American scholarly literature already cite each other's research. The difficulty is they tend not to be concerned with each other's signature concepts or when they discuss another field's signature concept use different publications to support their arguments. Two areas where mutual interests have proved to be more important than individual differences is firstly in conceptions of teaching and their 
impact on student success and then with the growing a sense that both fields are in a similar situation in terms of decreasing public funding. Nevertheless, it will require an acknowledgement of the other field's conceptual antecedents for there to be any opening up of two distinctive research fields to greater collaboration among their researchers.

Assuming that greater convergence for the North American and non-North American fields is a desirable goal then we need to recognize that a single logic that unites these fields is unlikely to develop naturally. The purpose of empirical studies like this intertextual review of the citation practices of authors in three North American journals in higher education is to achieve greater insight into the dynamics that influence development in the field. It is within these journals that researchers acquire their reputation as accomplished authors or researchers who address important questions for higher education teaching and learning. Naturally, a subjective case could be made for the influence of any individual researcher and many will have their own personal preferences for five different signature concepts for the North American field of higher education teaching and learning. However, the six key researchers and the five main concepts described above have become the taken-for-granted positions of those who publish in the North American research literature. Those who do not recognize this history will find a major barrier for entry for new ideas regardless of their background.

\section{References}

Astin, A. W. (1993). What matters in college. San Francisco: Jossey-Bass.

Barnett, R. (1988). Entry and exit performance indicators for higher education: Some policy and research issues. Assessment and Evaluation in Higher Education, 13, 16-30.

Barnett, R. (1992). Improving higher education: Total quality care. Buckingham: Society for Research into Higher Education \& Open University Press.

Barnett, R. (1994). Recovering an academic community: Above but not beyond. In R. Barnett (Ed.), Academic community: Discourse or discord? (pp. 3-20). London: Jessica Kingsley Publishers.

Biggs, J. B. (1978). Individual and group differences in study processes. British Journal of Educational Psychology, 48(3), 266-279.

Biggs, J. B. (1987). Student approaches to learning and studying. Hawthorn, Victoria: Australian Council for Educational Research.

Biggs, J. B. (1999). Teaching for quality learning at university. Buckingham: Society for Research into Higher Education \& Open University Press.

Bourdieu, P. (1983). The field of cultural production or the economic world reversed. Poetics, 12, 311-356.

Bourdieu, P. (1985). The market of symbolic goods. Poetics, 14, 13-43.

Bourdieu, P. (1991). Language and symbolic power. Cambridge: Polity Press.

Bourdieu, P. (1995). Rules of art: Genesis and structure of the literary field. London: Polity Press.

Entwistle, N. J., \& Ramsden, P. (1983). Understanding student learning. London: Croom Helm.

Entwistle, N., \& Tait, H. (1995). Approaches to studying and perceptions ofthe learning environment across disciplines. In N. Hativa, \& M. Marincovich (Eds.), Disciplinary differences in teaching and learning: Implications for practice (pp. 93-103). New Directions for Teaching and Learning No. 64. San Francisco: Jossey-Bass.

Haggis, T. (2009). Student learning research: A broader view. In M. Tight, K. H. Mok, J. Huisman, \& C. C. Morphew (Eds.), The Routledge international handbook of higher education (pp. 23-35). London: Routledge.

Kandlbinder, P. (2013). Signature concepts of key researchers in higher education teaching and learning. Teaching in Higher Education, 18(1), 1-12.

Kuh, G. D., Hayek, J. C., Carini, R. M., Ouimet, J. A., Gonyea, R. M., \& Kennedy, J. (2001). NSSE Technical and Norms Report. Bloomington: Indiana University Center for Postsecondary Research and Planning.

Kuh, G. D., Schuh, J. H., Whitt, E. J., \& Associates. (1991). Involving colleges: Successful approaches to fostering student learning and development outside the classroom. San Francisco: Jossey-Bass. 
Kuh, G. D., Vesper, N., Connolly, M. R., \& Pace, C. R. (1997). College Student Experiences Questionnaire: Revised Norms for the third edition. Bloomington: Indiana University, Center for Postsecondary Research and Planning.

Kuh, G. D., \& Whitt, E. J. (1988). The invisible tapestry: Culture in American colleges and universities. ASHE-ERIC Higher Education Report, No. 1. Washington, DC: Association for the Study of Higher Education.

Pascarella, E., \& Terenzini, P. T. (1991). How college affects students. San Francisco: Jossey-Bass.

Prosser, M., \& Trigwell, K. (1999). Understanding learning and teaching: the experience in higher education. Buckingham: Open University Press.

Ramsden, P., \& Moses, I. (1992). Associations between research and teaching in Australian universities. Higher Education, 23(3), 273-295.

Slaughter, S., \& Leslie, L. L. (1997). Academic capitalism: Politics, policies, and the entrepreneurial university. Baltimore: Johns Hopkins University Press.

St. John, E. P. (1990a). Price response in persistence decisions: An analysis of the high school and beyond senior cohort. Research in Higher Education, 31(4), 387-403.

St. John, E. P. (1990b). Price response in persistence decisions: An analysis of the high school and beyond senior cohort. Research in Higher Education, 31, 387-403.

St. John, E. P. (1994). Prices, productivity, and investment: Assessing financial strategies in higher education. (ASHE-ERIC Higher Education Reports. 1994 Report Three). Washington, DC: The George Washington University.

St. John, E. P. (1999). Evaluating state student grant programs: A case study of Washington's grant program. Research in Higher Education, 40(2), 149-169.

St. John, E. P. (2003). Refinancing the college dream: Access, equal opportunity, and justice for taxpayers. Baltimore. MD: Johns Hopkins University Press.

St. John, E., Andrieu, S., Oescher, J., \& Starkey, J. (1994). The influence of student aid on within-year persistence by traditional college-age students at four-year colleges. Research in Higher Education, 35 , 455-480.

St. John, E. P., Kirshstein, R. J., \& Noell, J. (1991). The effects of student aid on persistence: A sequential analysis of the high school and beyond senior cohort. Review of Higher Education, 14, 383-406.

St. John, E. P., \& Noell, J. (1989). The effects of student financial aid on access to higher education: An analysis of progress with special consideration of minority enrollment. Research in Higher Education, 30, 563-582.

St. John, E. P., \& Starkey, J. B. (1995). An alternative to net price: Assessing the influence of prices and subsidies on within-year persistence. Journal of Higher Education, 66, 156-186.

Thompson, J. B. (2005). Books in the digital age: The transformation of academic and higher education publishing in Britain. Cambridge: Polity Press.

Thompson, G., \& Yiyun, Ye. (2001). Evaluation of reporting verbs used in academic papers. Applied Linguistics, 12(4), 365-382.

Tierney, W. G., \& Bensimon, E. M. (1996). Promotion and tenure: community and socialization in academe. New York: State University of New York.

Tight, M. (2003). Researching Higher Education. Maidenhead: Society for Research into Higher Education \& Open University Press.

Tight, M. (2007). Bridging the Divide: A comparative analysis of articles in higher education journals published inside and outside North America. Higher Education, 53, 235-253.

Tight, M. (2012). Higher education research 2000-2010: Changing journal publication patterns. Higher Education Research \& Development, 31(5), 723-740.

Tinto, V. (1993). Leaving college: Rethinking the causes and cures of student attrition (2nd ed.). Chicago: The University of Chicago Press.

Trigwell, K., \& Prosser, M. (1991). Improving the quality of student learning: the influence of learning context and student approaches to learning on learning outcomes. Higher Education, 22, 251-266.

Trigwell, K., \& Prosser, M. (1996). Congruence between intention and strategy in university science teachers approaches to teaching. Higher Education, 32, 77-87.

Trigwell, K., Prosser, M., \& Waterhouse, F. (1999). Relations between teachers approaches to teaching and students approaches to learning. Higher Education, 37, 57-70. 